\title{
Particle Directional Conveyance under Longitudinal Vibration by considering the Trough Surface Texture: Numerical Simulation Based on the Discrete Element Method
}

\author{
Huazhi Chen $\mathbb{D}$, Shengyuan Jiang $\mathbb{D}$, Rongkai Liu $\mathbb{D}$, and Weiwei Zhang $\mathbb{D}$ \\ State Key Laboratory of Robotics and System, Harbin Institute of Technology, No. 92, Xidazhi Street, Nangang District, \\ Harbin 150001, China \\ Correspondence should be addressed to Shengyuan Jiang; jiangshy@hit.edu.cn
}

Received 1 November 2017; Revised 16 January 2018; Accepted 29 January 2018; Published 26 February 2018

Academic Editor: Mickaël Lallart

Copyright (C) 2018 Huazhi Chen et al. This is an open access article distributed under the Creative Commons Attribution License, which permits unrestricted use, distribution, and reproduction in any medium, provided the original work is properly cited.

\begin{abstract}
Particles can move directionally in a trough with finlike asperities under longitudinal vibrations. Here, we present an analysis of the particle conveyance mechanism and the influence of the asperity shape on the particle conveyance capacity by employing a numerical simulation based on the discrete element method (DEM). A dynamic-static matching method is proposed to characterize the three microcontact parameters in the simulation: the restitution coefficient, static friction coefficient, and rolling friction coefficient. The simulation shows that the asymmetric force induced by the finlike asperities and its cumulative effect over time lead to the particle directional conveyance. The conveyance velocity increases with increasing vibration time and is related to the median coordination number. The asperity height and slope inclination angles determine the trough shape and distance between two asperities directly. An undersized or oversized distance reduces the steady conveyance velocity. We find the optimal distance to be between one and two particle diameters.
\end{abstract}

\section{Introduction}

In situ resource utilization (ISRU) is an important basis for establishing a future lunar base. ISRU involves using lunar regolith and rock as building materials and manufacturing metal and oxygen from these raw materials [1$3]$. In this process, conveyance is essential for raw material, particularly granular materials (e.g., lunar regolith), as shown in Figure 1. In most cases, the granular materials must be transported from the ground to a certain height automatically and continuously. Considering the constraints of lunar engineering, a vibratory conveyor with a simple configuration that consumes relatively little energy is more suitable than a belt conveyor [4]. Furthermore, a vibratory conveyor can transport high-temperature or corrosive materials because its trough can be readily made from a refractory and corrosion-resistant material. These properties make such conveyors widely preferred in the metallurgical and chemical industries. In view of the above advantages, several investigations have been conducted to extend vibratory conveyance theory and improve the performance of conveyors in engineering. Two types of vibratory conveyor are currently applied in practice and are classified according to the vibration direction relative to the trough surface. The first features sinusoidal vibration acting obliquely on the trough [5-8], and the second features vibration parallel to the axis of the trough (i.e., the longitudinal direction) but with a nonsinusoidal profile $[9,10]$. Materials cannot be transported directionally if the trough vibrates longitudinally in a sinusoidal form. However, such transport is enabled if the trough has an appropriate surface morphology, for example, a sawtooth texture [11]. We previously reported such behavior [12]. This topic merits comprehensive study because of its potential value for improving the performance of current conveyors.

Generally, granular materials are considered to be a point mass for convenient theoretical analysis, but this simplification cannot reflect the actual properties of such materials. 


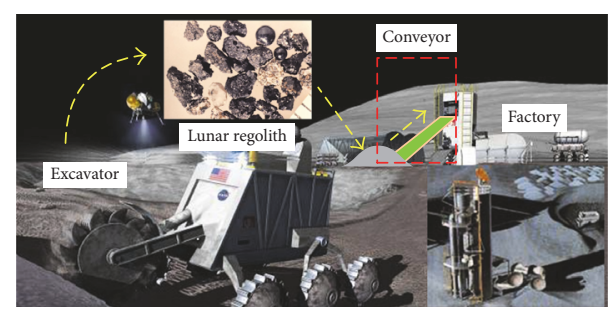

FIGURE 1: Conception of lunar regolith excavation and conveyance to establish a lunar base [2].

Previous research has established that granular materials exhibit complex properties under vibration, such as convection, heaping, size separation, and even climbing in narrow channels [13-16]. A large number of particle interactions leads to a kinestate distinct from that of a single body on a vibratory conveyor. The presence of a variety of multiple types of particles, particularly tiny and opaque particles, makes it challenging to experimentally study detailed particle motion in a trough. Fortunately, numerical simulations based on the discrete element method (DEM), introduced by Cundall and Strack [17], can be used to study this configuration. The advantage of the DEM is that it provides detailed particlescale information for analysis. DEM simulations have provided an effective means to study granular material behavior over several decades of development [18-22].

In our previous work, we studied particle directional conveyance in a trough with sawtooth asperities using DEM simulations [12]. The primarily goal was to study the influence of the vibration conditions on the particle conveyance capacity. For the DEM simulations, the accuracy of the parameters set for the calculation can significantly affect the reliability of the result. In the simulation, we characterized particle microcontact parameters such as the static friction coefficient by matching the angle of repose (AOR) [23, 24] with the experimental value. This method is reliable when considering particles with static or quasi-static characteristics but is not completely suitable for studying the dynamic characteristics, which is an unavoidable issue as long as we employ DEM simulation in this context.

For the trough surface morphology, Farkas et al. [25] observed that the size of the finlike asperities in an annular channel can affect particle horizontal conveyance under vertical vibrations. Thus, we chose to explore the influence under a longitudinal vibration. Distinct from our previous work, in this study, we focused on the mechanism of particle directional conveyance and the influence of the finlike asperity size on the conveyance capacity using DEM simulations. To improve the reliability of the simulation results, we propose a dynamic-static matching method to determine the particle microcontact parameters. This paper is organized as follows. In Section 2, we introduce the DEM model used to calculate the contact force and torque. In Section 3, we review the simulation conditions and the dynamic-static matching method to characterize the particle microcontact parameters. In Section 4, we present and discuss the simulation results. Finally, we report our conclusions in Section 5 .

\section{DEM Model Description}

In our simulation, a three-dimensional DEM based on the soft-sphere model [26-28] was used. The particles were considered to be dry and clean; that is, there were no cohesive forces and no liquid bridges between the particles. Each particle exhibited two types of movement, translational motion and rotational motion, as governed by Newton's second law:

$$
\begin{aligned}
& m_{i} \frac{\mathrm{d} \mathbf{v}_{i}}{\mathrm{~d} t}=m_{i} \mathbf{g}+\sum_{j=1}^{n_{i}} \mathbf{F}_{i j}, \\
& I_{i} \frac{\mathrm{d} \boldsymbol{\omega}_{i}}{\mathrm{~d} t}=\sum_{j=1}^{n_{i}} \mathbf{T}_{i j}
\end{aligned}
$$

where $\mathbf{v}_{i}$ and $\boldsymbol{\omega}_{i}$ are the translational and angular velocity vectors of particle $i$, respectively; $m_{i}$ and $I_{i}$ are the mass and the rotational inertia of particle $i$, respectively; $\mathbf{g}$ is the gravitational acceleration; $n_{i}$ is the number of particles $j$ in collision with particle $i$; and $\mathbf{F}_{i j}$ and $\mathbf{T}_{i j}$ are the contact force and torque generated between particles $i$ and $j$, respectively, and are composed of several components: namely,

$$
\begin{aligned}
& \mathbf{F}_{i j}=\mathbf{F}_{n, i j}+\mathbf{F}_{t, i j}, \\
& \mathbf{T}_{i j}=\mathbf{T}_{n, i j}+\mathbf{T}_{t, i j}+\mathbf{T}_{\mathrm{r}},
\end{aligned}
$$

where $\mathbf{F}_{n, i j}$ and $\mathbf{F}_{t, i j}$ are the normal and the tangential forces, respectively, and $\mathbf{T}_{n, i j}$ and $\mathbf{T}_{t, i j}$ are the torques caused by the normal force and the tangential force, respectively. $\mathbf{T}_{\mathrm{r}}$ is the rolling friction torque when relative rotation occurs between the contacting particles.

Due to the absence of cohesive forces and liquid bridges, we chose the no-slip Hertz-Mindlin contact model [29] to calculate $\mathbf{F}_{i j}$ and $\mathbf{T}_{i j}$. This model is based on the classical Hertz theory along the normal direction [30] and the work of Mindlin [31] along the tangential direction. Depending on the model, the contact forces that include particle-particle and particle-wall interactions are as follows:

Normal force

$$
\begin{aligned}
& \mathbf{F}_{n, i j} \\
& \quad=\left(-\frac{4}{3} E^{*} \sqrt{R^{*}\left(\delta_{n, i j}\right)^{3}}-2 \sqrt{\frac{5}{6}} \beta_{c} \sqrt{S_{n} m^{*}}\left|\mathbf{v}_{n, i j}\right|\right) \mathbf{n}_{i j} .
\end{aligned}
$$

Tangential force

$$
\begin{aligned}
& \mathbf{F}_{t, i j} \\
& = \begin{cases}-\mathbf{F}_{t e, i j}^{n}-2 \sqrt{\frac{5}{6}} \beta_{\mathrm{c}} \sqrt{S_{t} m^{*}} \mathbf{v}_{t, i j} & \text { for }\left|\mathbf{F}_{t, i j}\right| \leq \mu_{\mathrm{s}}\left|\mathbf{F}_{n, i j}\right| \\
\frac{-\mu_{\mathrm{s}}\left|\mathbf{F}_{n, i j}\right| \mathbf{v}_{t, i j}}{\left|\mathbf{v}_{t, i j}\right|} & \text { for }\left|\mathbf{F}_{t, i j}\right|>\mu_{\mathrm{s}}\left|\mathbf{F}_{n, i j}\right|,\end{cases} \\
& \mathbf{F}_{t e, i j}^{n}=\mathbf{F}_{t e, i j}^{n-1}+S_{t}^{n} \Delta \boldsymbol{\delta}_{t, i j} \text { for } \Delta \mathbf{F}_{n, i j} \geq 0, \\
& \mathbf{F}_{t e, i j}^{n}=\mathbf{F}_{t e, i j}^{n-1}\left(\frac{S_{t}^{n}}{S_{t}^{n-1}}\right)+S_{t}^{n} \Delta \boldsymbol{\delta}_{t, i j} \quad \text { for } \Delta \mathbf{F}_{n, i j}<0 .
\end{aligned}
$$




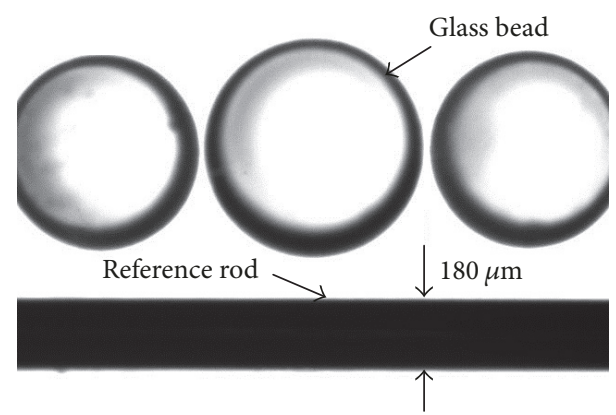

Figure 2: Micrograph of a glass bead to determine the particle model for the simulation.

Torque

$$
\begin{aligned}
\mathbf{T}_{n, i j} & =R_{i} \mathbf{n}_{i j} \times \mathbf{F}_{n, i j}, \\
\mathbf{T}_{t, i j} & =R_{i} \mathbf{n}_{i j} \times \mathbf{F}_{t, i j}, \\
\mathbf{T}_{\mathrm{r}} & =-\mu_{\mathrm{r}}\left|\mathbf{F}_{n, i j}\right| R_{i} \boldsymbol{\omega}_{n i} .
\end{aligned}
$$

The parameters $\mu_{\mathrm{s}}$ and $\mu_{\mathrm{r}}$ are the static and rolling friction coefficients, respectively; $\delta_{n, i j}$ and $\boldsymbol{\delta}_{t, i j}$ are the normal overlap and tangential displacements, respectively; $\mathbf{v}_{n, i j}$ and $\mathbf{v}_{t, i j}$ are the relative normal and tangential velocities, respectively; $\mathbf{n}_{i j}$ is the unit vector pointing from the center of particle $i$ to particle $j ; \boldsymbol{\omega}_{n i}$ is the unit angular velocity vector when a relative rotation occurs; and $E^{*}, R^{*}$, and $m^{*}$ are the equivalent Young's modulus, particle radius, and mass, respectively [32].

In (4a), (4b), and (4c), the superscript $n$ is the time step number, $\mathbf{F}_{t e, i j}$ is the elastic component of the tangential force, and $\Delta \boldsymbol{\delta}_{t, i j}$ and $\Delta \mathbf{F}_{n, i j}$ are the tangential displacement increment and the normal force increment, respectively. $\mathbf{F}_{t e, i j}$ depends on the interaction phase. If the interaction is in the loading phase, the increment of $\mathbf{F}_{t e, i j}$ is simply proportional to $\Delta \boldsymbol{\delta}_{t, i j}($ see $(4 \mathrm{~b}))$. If the interaction is in the unloading phase, then the elastic tangential force at the previous time step should be reduced (see (4c)) due to the reduction in the contact area during unloading. This modification is intended to prevent the creation of spurious energy [33].

The parameters $S_{n}, S_{t}$, and $\beta_{c}$ are given by

$$
\begin{aligned}
& S_{n}=2 E^{*} \sqrt{R^{*} \delta_{n, i j}}, \\
& S_{t}=8 G^{*} \sqrt{R^{*} \delta_{n, i j}}, \\
& \beta_{c}=\frac{\ln e}{\sqrt{\ln ^{2} e+\pi^{2}}},
\end{aligned}
$$

where $G^{*}$ is the equivalent shear modulus and $e$ is the restitution coefficient.

Based on the no-slip Hertz-Mindlin contact model and the matched calculation procedure, the particle's kinestate in each time step is obtained. In this work, the EDEM software package [34] was employed for the numerical simulation. However, before calculation, the conditions should be set in detail, particularly the microcontact parameters $e, \mu_{\mathrm{s}}$, and $\mu_{\mathrm{r}}$, as described in Section 3.

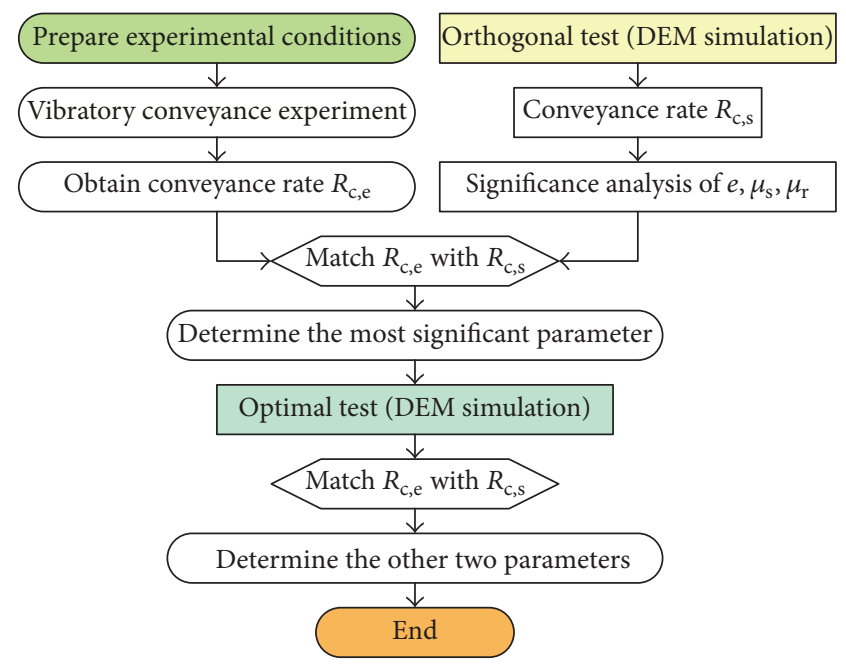

FIgURE 3: Procedure to determine the microcontact parameters for the DEM simulation.

\section{Simulation Setting}

3.1. Three-Dimensional Particle Model. The particle was defined as a glass bead of $0.4 \mathrm{~mm}$ to $0.6 \mathrm{~mm}$ (average $0.5 \mathrm{~mm}$ ) diameter and $2,468 \mathrm{~kg} / \mathrm{m}^{3}$ real density. This bead presented a nearly perfect spherical shape according to the micrograph in Figure 2 (a reference rod was used to estimate the glass bead diameter). Thus, we employed a spherical particle with a uniform diameter of $0.5 \mathrm{~mm}$ for the simulation, and we tentatively ignored the effect of particle size variation in this study.

3.2. Microcontact Parameter Matching. The primary challenge in DEM simulation is to determine the material mechanical parameters and the microcontact parameters. The material mechanical parameters, which include the density, Young's modulus, and Poisson's ratio, can be determined experimentally or by consulting references. However, the microcontact parameters cannot be obtained accurately using this method. Generally, such parameters are determined by matching a parameter that is measured easily in both simulation and experiment $[35,36]$. In this study, the objective parameter we used was the conveyance rate $\left(R_{\mathrm{c}}\right)$, which is defined as the ratio of the transported volume per second to the total volume. Relative to matching the stress in a triaxial compression test [37] or the AOR in a sandglass test [24], this method is better suited to study the particle dynamic motion and obtain more accurate microcontact parameters. The main procedure of the method is described in Figure 3, and the details are introduced in Figure 3.

Figure 4 shows a sketch of the experiment conditions. The trough was made from synthetic resin and augmented with finlike asperities along a surface measuring $100 \mathrm{~mm} \times$ $10 \mathrm{~mm}\left(L_{\mathrm{T}} \times W_{\mathrm{T}}\right)$, as shown in Figure 4(a). The trough was positioned obliquely to obtain an inclination angle $(\theta)$ of $10^{\circ}$. The height of each asperity $(h)$ was $0.3 \mathrm{~mm}$. The tangent values of the slope inclination angles $\alpha$ and $\beta$ were $6 / 17$ and 2 , respectively. A silo with an inner diameter $\left(d_{0}\right)$ of $3 \mathrm{~mm}$ was placed under the discharge hole to evaluate the conveyance 


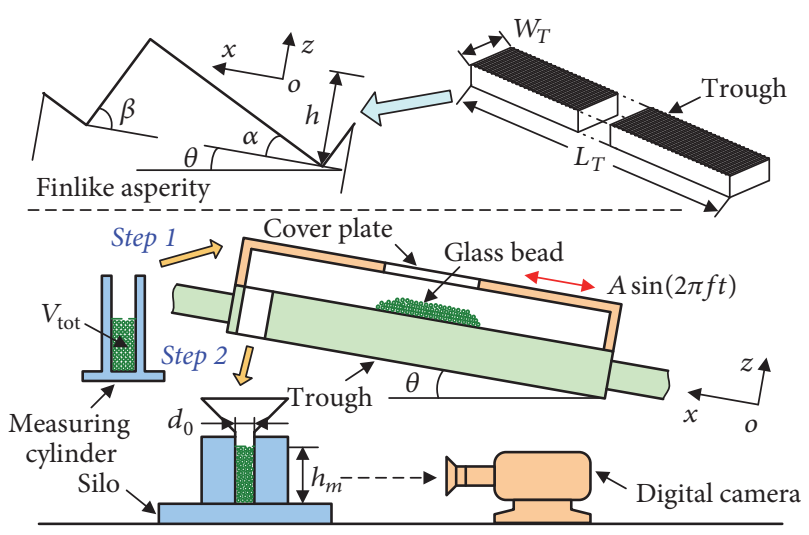

(a)

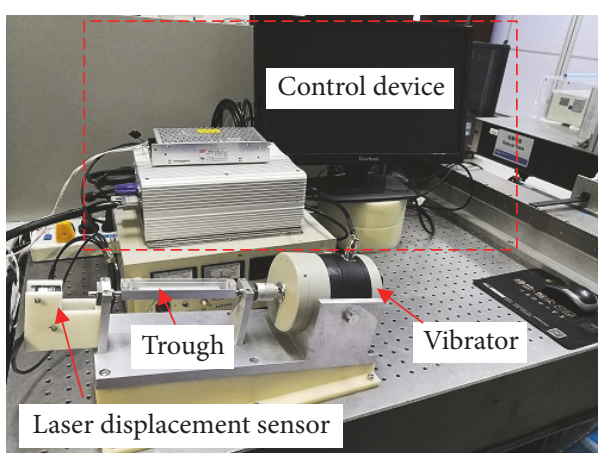

(b)

FIGURE 4: Sketch of the experimental conditions. (a) The trough with finlike asperities and the main experimental process. (b) Experimental equipment for vibratory conveyance.

capacity. In addition, a cover plate was attached to the trough to prevent the glass beads from being ejected from the trough during vibration.

Vibration was obtained using a vibrator (HEV-50, manufactured by Foneng Technology and Industrial (Nanjing) Co., Ltd., Nanjing, China) with an adjustable amplitude $(A)$ and frequency $(f)$ using a control device, as depicted in Figure 4(b). In this study, the vibration was sinusoidal:

$$
x=A \sin (2 \pi f t),
$$

where $x$ is the displacement of the trough. The real-time vibration was monitored using a laser displacement sensor (Panasonic HG-C1030).

In the experiment, a known volume of glass beads ( $V_{\text {tot }}$ $=170 \mathrm{~mm}^{3}$ ) was placed on the middle of the trough surface containing the finlike asperities (Step 1). Then, the trough was vibrated along its central axis, and the glass beads were collected by the silo when the beads were discharged from the discharge hole $(+x$-direction in Figure 4 , Step 2$)$. The collection process was recorded using a digital camera to ascertain the heaping height $\left(h_{\mathrm{m}}\right)$. The mass of the glass beads was sufficiently small that its influence on the vibration amplitude $A$ was ignored.

When $A=0.3 \mathrm{~mm}$ and $f=50 \mathrm{~Hz}$, the heaping height increased over time until all of the glass beads were discharged, as shown in Figure 5. To evaluate the conveyance rate, we selected an interval during which the relationship between $h_{\mathrm{m}}$ and $t$ was approximately linear. We considered that the relationship would be linear if the correlation coefficient $(r)$ was greater than 0.9 in this study. The corresponding conveyance rate is

$$
R_{\mathrm{c}, \mathrm{e}}=\frac{\pi d_{0}^{2}}{4 V_{\mathrm{tot}}} \cdot \frac{\mathrm{d} h_{\mathrm{m}}}{\mathrm{d} t}, \quad t \in[6,12] .
$$

According to the fitting curve in Figure $5, R_{c, \mathrm{e}}$ was $0.089 \mathrm{~s}^{-1}$ in the experiment.

In the DEM simulation, an assembly of 1,500 spherical particles (the total occupation was approximately $V_{\text {tot }}=$ $170 \mathrm{~mm}^{3}$ ) was employed and completely generated from the

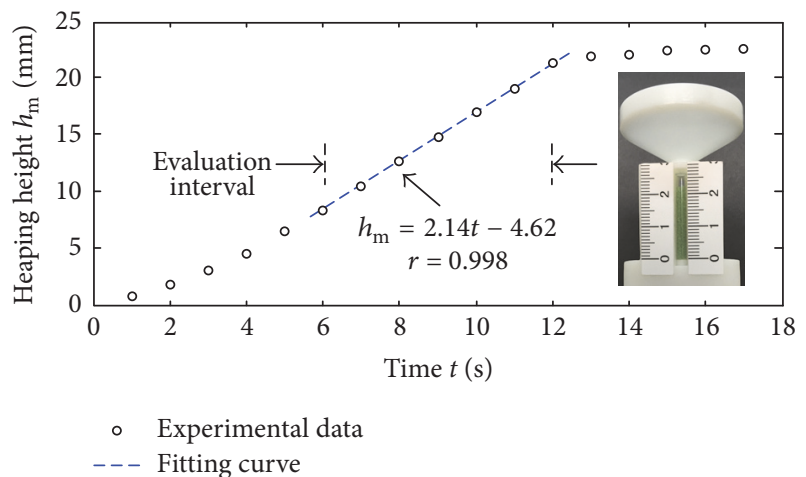

FIGURE 5: Relationship between the experimental heaping height and time.

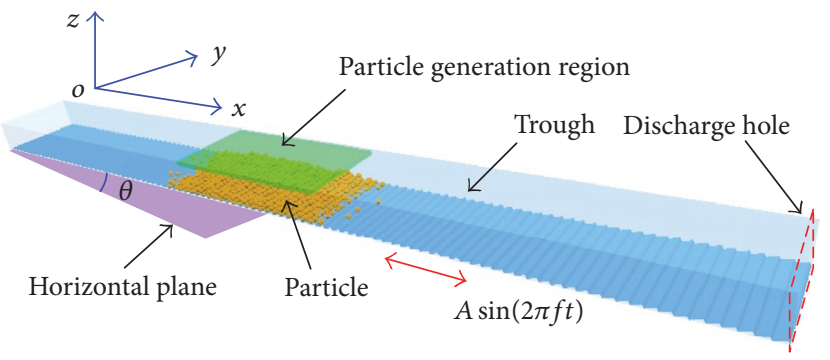

FIGURE 6: Sketch of the DEM simulation conditions.

particle generation region in $1 \mathrm{~s}$, as shown in Figure 6. The region measured $20 \mathrm{~mm} \times 10 \mathrm{~mm}$. After generation, the trough vibrated along the $x$-direction for $10 \mathrm{~s}$. The size of the trough and finlike asperity, the inclination angle $(\theta)$, and the vibration parameters ( $A$ and $f$ ) were the same as in the experiment. To shorten the actual time for simulation, we used the particle number instead of the heaping height to define $R_{\mathrm{c}, \mathrm{s}}$ :

$$
R_{\mathrm{c}, \mathrm{s}}=\frac{1}{N_{\mathrm{tot}}} \cdot \frac{\mathrm{d} N_{\mathrm{c}}}{\mathrm{d} t}
$$


TABLE 1: Material mechanical parameters of the trough and particles.

\begin{tabular}{lcc}
\hline Parameter & Trough & Particles \\
\hline Density $\rho\left[\mathrm{kg} / \mathrm{m}^{3}\right]$ & 1070 & 2468 \\
Shear modulus $G[\mathrm{~Pa}]$ & $8.63 \times 10^{8}$ & $5 \times 10^{7}$ \\
Poisson's ratio $\gamma[-]$ & 0.39 & 0.23 \\
\hline
\end{tabular}

TABLE 2: Microcontact parameter levels in the orthogonal test.

\begin{tabular}{lccc}
\hline Level number & (A) $e_{\mathrm{p}-\mathrm{t}}[-]$ & (B) $\mu_{s}[-]$ & (C) $\mu_{r}[-]$ \\
\hline 1 & 0.3 & 0.5 & 0.08 \\
2 & 0.5 & 0.3 & 0.06 \\
3 & 0.7 & 0.9 & 0.04 \\
4 & 0.9 & 0.7 & 0.10 \\
\hline
\end{tabular}

where $N_{\text {tot }}=1,500$ is the total particle number and $N_{c}$ is the discharged particle number. Similarly, $R_{\mathrm{c}, \mathrm{s}}$ was also obtained according to the linear part of the $t-N_{c}$ curve.

The trough and the particle material mechanical parameters are listed in Table 1. The particle Poisson's ratio was based on Tatemoto et al.s work [38]. The shear modulus was set to $5 \times 10^{7} \mathrm{~Pa}$ to improve the computational efficiency. Though this value is small for glass, the influence can be revised using microcontact parameter matching as described below. Other parameters were obtained from the raw material suppliers.

In the DEM simulation, the time step $\Delta t$ depends primarily on the particle material mechanical parameters [39]. In this study, $\Delta t$ was $1.51 \times 10^{-6} \mathrm{~s}$, and the data were recorded every $0.001 \mathrm{~s}$.

It is necessary to analyze the significance of the microcontact parameters before matching. To this end, an orthogonal test is simple and appropriate. Generally, the restitution coefficient $e$ and static friction coefficient $\mu_{\mathrm{s}}$ each lies between 0 and 1 , and the rolling friction coefficient $\mu_{\mathrm{r}}$ lies between 0 and 0.1. According to Tatemoto et al's work [38], the particleparticle restitution coefficient $e_{\mathrm{p}-\mathrm{p}}$ is 0.9 . Assuming that the static and the rolling friction coefficients of the particleparticle and particle-trough interactions are the same (i.e., $\mu_{\mathrm{s}, \mathrm{p}-\mathrm{p}}=\mu_{\mathrm{s}, \mathrm{p}-\mathrm{t}}=\mu_{\mathrm{s}}$ and $\left.\mu_{\mathrm{r}, \mathrm{p}-\mathrm{p}}=\mu_{\mathrm{r}, \mathrm{p}-\mathrm{t}}=\mu_{\mathrm{r}}\right)$, the number of the undetermined microcontact parameters is reduced from 5 to 3 . The resulting levels of each parameter in the orthogonal test are listed in Table 2.

The orthogonal test included 3 factors and 4 levels; thus, 16 subsimulations were required. The relationship between $N_{\mathrm{c}}$ and $t$ in each subsimulation is shown in Figure 7, and the conveyance rates $R_{c, s}$ are listed in Table 3 .

The intuitive analysis (range analysis) in the orthogonal tests [40] is a simple method to estimate the significance of the factors. A greater range $\left(R_{\mathrm{s}}\right)$ implies that the corresponding factor is more significant. Based on the result in Table 3, we determined that the restitution coefficient of the particle-trough $\left(e_{\mathrm{p}-\mathrm{t}}\right)$ was the most significant factor and that the rolling friction coefficient $\mu_{\mathrm{r}}$ produced less of an effect on the conveyance rate. In addition, the results of simulations numbers 3 and 4 were more similar to $R_{c, e}$. Thus, the parameter $e_{\mathrm{p}-\mathrm{t}}$ was determined to be 0.3 in this study.
TABLE 3: Orthogonal test scheme and results.

\begin{tabular}{lcccc}
\hline $\begin{array}{l}\text { Subsimulation } \\
\text { number }\end{array}$ & $\begin{array}{c}\text { (A) Level } \\
\text { number }\end{array}$ & $\begin{array}{c}\text { (B) Level } \\
\text { number }\end{array}$ & $\begin{array}{c}\text { (C) Level } \\
\text { number }\end{array}$ & $R_{c, s}\left(\mathrm{~s}^{-1}\right)$ \\
\hline 1 & 1 & 1 & 1 & 0.124 \\
2 & 1 & 2 & 2 & 0.231 \\
3 & 1 & 3 & 3 & 0.074 \\
4 & 1 & 4 & 4 & 0.077 \\
5 & 2 & 2 & 4 & 0.306 \\
6 & 2 & 1 & 3 & 0.194 \\
7 & 2 & 4 & 2 & 0.153 \\
8 & 2 & 3 & 1 & 0.133 \\
9 & 3 & 3 & 2 & 0.193 \\
10 & 3 & 4 & 1 & 0.190 \\
11 & 3 & 1 & 4 & 0.221 \\
12 & 3 & 2 & 3 & 0.252 \\
13 & 4 & 4 & 3 & 0.028 \\
14 & 4 & 3 & 4 & 0.053 \\
15 & 4 & 2 & 1 & 0.049 \\
16 & 4 & 1 & 2 & 0.041 \\
\hline Range $R_{s}$ & 0.684 & 0.390 & 0.161 & \\
\hline
\end{tabular}

Although the influence of the rolling friction coefficient on the conveyance rate was not prominent, this influence should be determined as accurately as possible. An effective method to perform this evaluation is the static matching method, also known as AOR matching in this study. The procedure of measuring the AOR is as follows: (a) place a hopper on the horizontal plane; (b) fill the hopper with a certain volume of particles; (c) hoist the hopper slowly until the particles are completely discharged; and (d) measure the AOR $\theta_{\mathrm{r}}$. Figure 8 illustrates the procedure.

The experimental value of $\operatorname{AOR}\left(\theta_{\mathrm{r}, \mathrm{e}}\right)$ was $25.4^{\circ}$, while the simulation values $\left(\theta_{\mathrm{r}, \mathrm{s}}\right)$ based on simulations numbers 3 and 4 were $28.3^{\circ}$ and $34.8^{\circ}$, respectively, as shown in Figure 9. The simulated value approached $\theta_{\mathrm{r}, \mathrm{e}}$ when $\mu_{\mathrm{r}}=0.04$ despite $\mu_{\mathrm{s}}$ being larger.

To determine the final values of $\mu_{\mathrm{s}}$ and $\mu_{\mathrm{r}}$, we employed an optimal test whose object was to match $\left(R_{\mathrm{c}, \mathrm{s}}, \theta_{\mathrm{r}, \mathrm{s}}\right)$ with $\left(R_{\mathrm{c}, \mathrm{e}}, \theta_{\mathrm{r}, \mathrm{e}}\right)$, with the conditions

$$
\left|\frac{R_{\mathrm{c}, \mathrm{s}}-R_{\mathrm{c}, \mathrm{e}}}{R_{\mathrm{c}, \mathrm{e}}}\right| \leq \xi\left(R_{\mathrm{c}}\right) \cap\left|\frac{\theta_{\mathrm{r}, \mathrm{s}}-\theta_{\mathrm{r}, \mathrm{e}}}{\theta_{\mathrm{r}, \mathrm{e}}}\right| \leq \xi\left(\theta_{\mathrm{r}}\right),
$$

where $\xi\left(R_{\mathrm{c}}\right)$ and $\xi\left(\theta_{\mathrm{r}}\right)$ were the allowable errors, both set as 0.05 . The results are shown in Figure 10 , where $\mu_{\mathrm{r}}=[0.03$, $0.04]$ and $\mu_{\mathrm{s}}=[0.3,0.5,0.7,0.9]$. The figure indicates that $R_{\mathrm{c}, \mathrm{s}}$ declined as $\mu_{\mathrm{s}}$ rose, while $\theta_{\mathrm{r}, \mathrm{s}}$ increased under the same $\mu_{\mathrm{r}}$. Based on the curves and allowable errors, the optimized intervals of $\mu_{\mathrm{s}}\left(A_{\mathrm{op}}\right)$ under various $\mu_{\mathrm{r}}$ were determined. Clearly, $R_{\mathrm{c}}$ was larger when $\mu_{\mathrm{r}}=0.03$, and the ultimate values of $\mu_{\mathrm{s}}$ and $\mu_{\mathrm{r}}$ were determined to be 0.8 and 0.03 , respectively.

By setting $e_{\mathrm{p}-\mathrm{p}}=0.9, e_{\mathrm{p}-\mathrm{t}}=0.3, \mu_{\mathrm{s}}=0.8$, and $\mu_{\mathrm{r}}=$ 0.03 , the conveyance rate $R_{\mathrm{c}, \mathrm{s}}$ and the $\operatorname{AOR} \theta_{\mathrm{r}, \mathrm{s}}$ were $0.091 \mathrm{~s}^{-1}$ and $26.1^{\circ}$, respectively, which further validated the reliability 

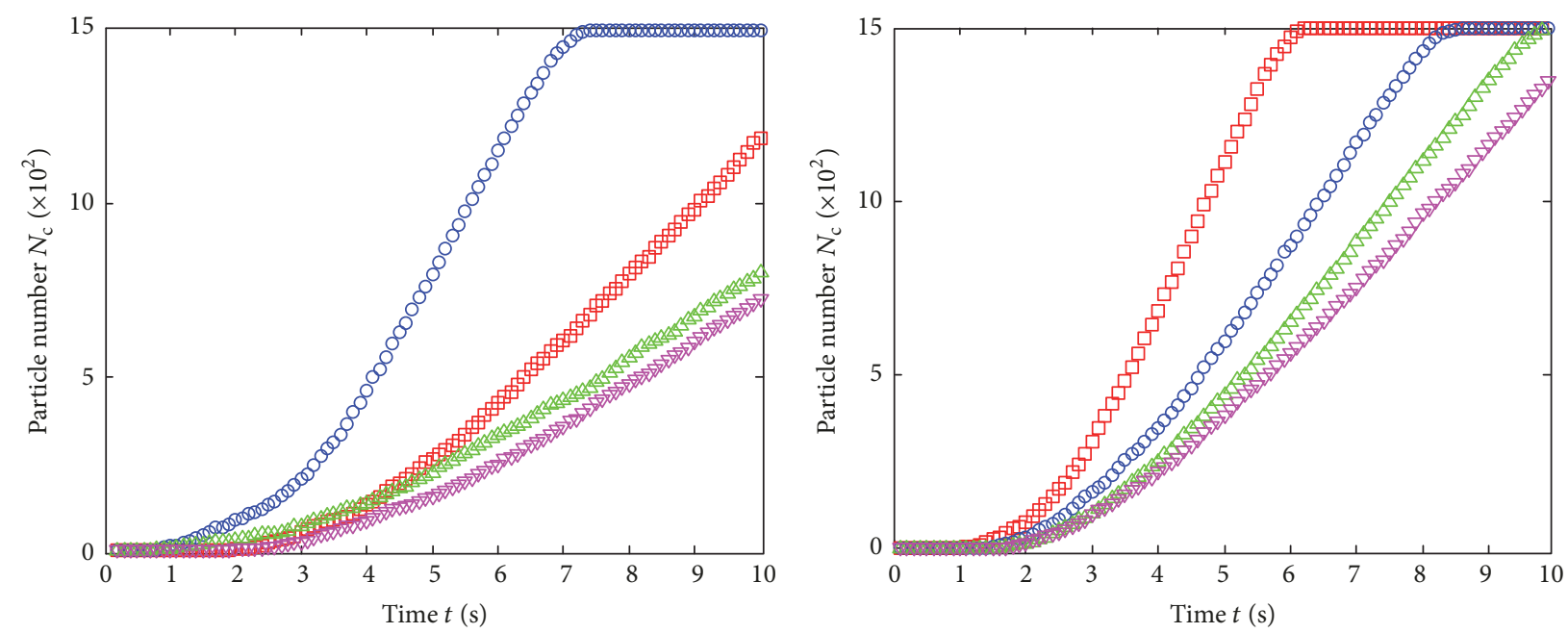
ㅁ $\mathrm{A}_{1} \mathrm{~B}_{1} \mathrm{C}_{1}$
- $\mathrm{A}_{1} \mathrm{~B}_{2} \mathrm{C}_{2}$
$\triangle \mathrm{A}_{1} \mathrm{~B}_{3} \mathrm{C}_{3}$
$\nabla \mathrm{A}_{1} \mathrm{~B}_{4} \mathrm{C}_{4}$
ㅁ $\mathrm{A}_{2} \mathrm{~B}_{2} \mathrm{C}_{4}$
- $\mathrm{A}_{2} \mathrm{~B}_{1} \mathrm{C}_{3}$

$\triangle \mathrm{A}_{2} \mathrm{~B}_{4} \mathrm{C}_{2}$

$\nabla \mathrm{A}_{2} \mathrm{~B}_{3} \mathrm{C}_{1}$

(a)

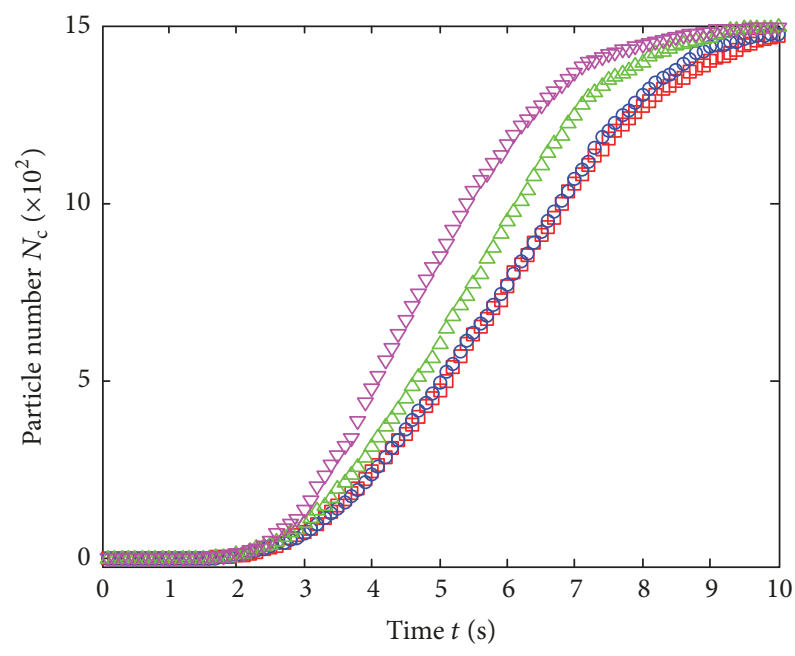

(b)

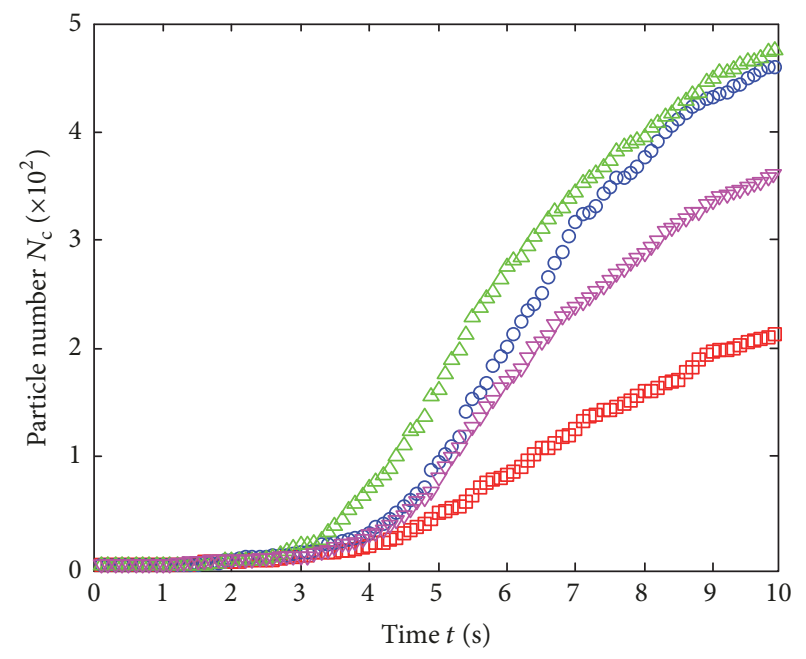
ㅁ $\mathrm{A}_{3} \mathrm{~B}_{3} \mathrm{C}_{2}$
$\triangle \mathrm{A}_{3} \mathrm{~B}_{1} \mathrm{C}_{4}$
ㅁ $\mathrm{A}_{4} \mathrm{~B}_{4} \mathrm{C}_{3}$
$\triangle \mathrm{A}_{4} \mathrm{~B}_{2} \mathrm{C}_{1}$
○ $\mathrm{A}_{3} \mathrm{~B}_{4} \mathrm{C}_{1}$
$\nabla \mathrm{A}_{3} \mathrm{~B}_{2} \mathrm{C}_{3}$
- $\mathrm{A}_{4} \mathrm{~B}_{3} \mathrm{C}_{4}$
$\nabla \mathrm{A}_{4} \mathrm{~B}_{1} \mathrm{C}_{2}$

(c)

(d)

FIGURE 7: Relationship between the discharged particle number and vibration time in each subsimulation: (a) $e_{\mathrm{p}-\mathrm{t}}=0.3$, (b) $e_{\mathrm{p}-\mathrm{t}}=0.5$, (c) $e_{\mathrm{p}-\mathrm{t}}$ $=0.7$, and $(\mathrm{d}) e_{\mathrm{p}-\mathrm{t}}=0.9$.

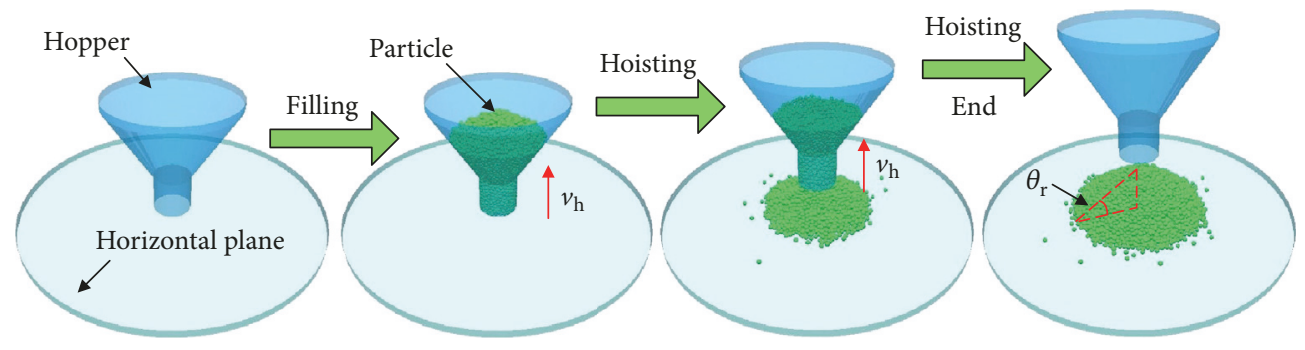

Figure 8: Procedure to measure the AOR. 


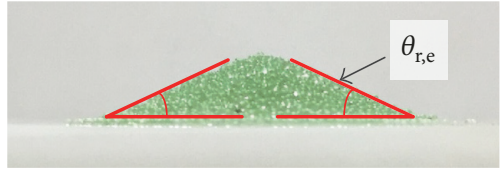

(a)

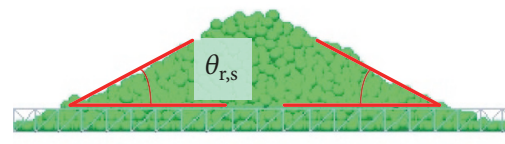

(b)

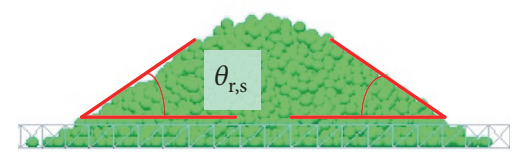

(c)

FIGURE 9: AOR: (a) $\theta_{\mathrm{r}, \mathrm{e}}=25.4^{\circ}$ in the experiment; (b) $\theta_{\mathrm{r}, \mathrm{s}}=28.3^{\circ}$ in the simulation (number 3); and (c) $\theta_{\mathrm{r}, \mathrm{s}}=34.8^{\circ}$ in the simulation (number $4)$.

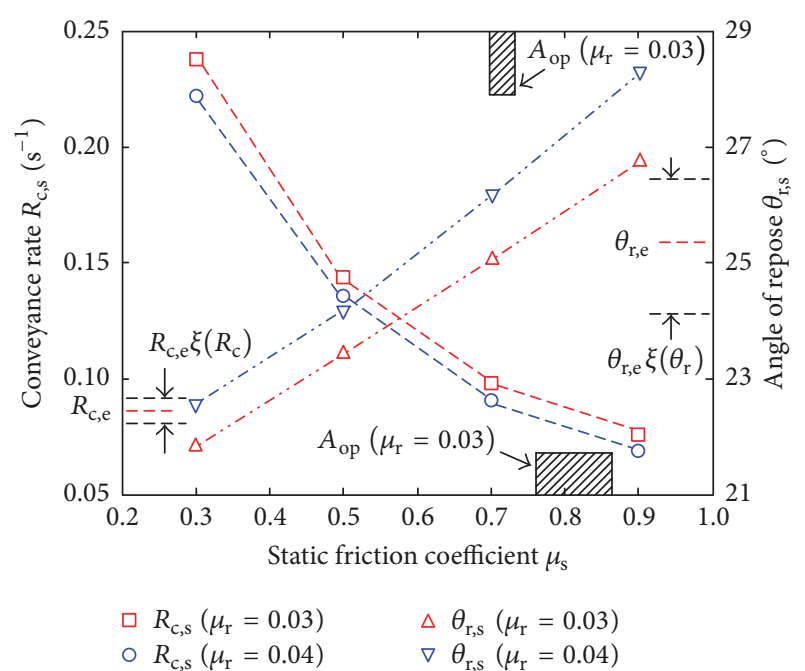

Figure 10: Relationship between $R_{\mathrm{c}, \mathrm{s}}, \theta_{\mathrm{r}, \mathrm{s}}$, and $\mu_{\mathrm{s}}$ under various values of $\mu_{\mathrm{r}}$.

of these predictions. Then, the total microcontact parameters for the DEM simulation were determined. The entire procedure is termed the dynamic-static matching method.

3.3. Dimensions of the Finlike Asperity. The parameters to determine the finlike asperity are $h, \alpha$, and $\beta$, as shown in Figure 4. To simplify our exposition, we introduce the following three dimensionless parameters:

$$
\begin{aligned}
& Y_{\mathrm{h}}=\frac{h}{d_{\mathrm{p}}}, \\
& Y_{\mathrm{a}}=\tan \alpha, \\
& Y_{\mathrm{b}}=\tan \beta,
\end{aligned}
$$

where $d_{\mathrm{p}}$ is the particle diameter $\left(d_{\mathrm{p}}=0.5 \mathrm{~mm}\right)$. The levels of each parameter are listed in Table 4 . The scope of the present study did not allow simulation of all possible combinations.

Another reason to use the DEM simulation instead of an experiment in this study is that smaller asperities (particularly when $Y_{\mathrm{h}}<0.6$ and $Y_{\mathrm{a}}>0.3$ ) are challenging to manufacture using conventional methods.

\section{Results and Discussion}

4.1. Why Do Particles Move Directionally? Figure 11 shows the particle directional conveyance in the trough, where $Y_{\mathrm{h}}=0.4$,
TABLE 4: Dimensionless parameters to describe the finlike asperity and associated levels.

\begin{tabular}{lccc}
\hline Level number & $Y_{\mathrm{h}}$ & $Y_{\mathrm{a}}$ & $Y_{\mathrm{b}}$ \\
\hline 1 & 0.2 & 0.1 & 1 \\
2 & 0.4 & 0.2 & 2 \\
3 & 0.6 & 0.3 & 3 \\
4 & 0.8 & 0.4 & 4 \\
5 & 1.0 & 0.5 & 5 \\
\hline
\end{tabular}

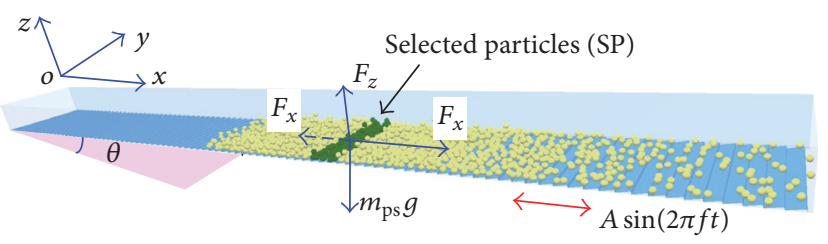

FIGURE 11: Particle directional conveyance in the trough $\left(Y_{\mathrm{h}}=0.4\right.$, $Y_{\mathrm{a}}=0.2$, and $\left.Y_{\mathrm{b}}=4\right)$.

$Y_{\mathrm{a}}=0.2$, and $Y_{\mathrm{b}}=4$. A portion of the particles was selected (SP) for analysis. Then, the force acting on the SP was divided into three components: the gravity $m_{\mathrm{ps}} g$, the force in the $x$ direction $F_{x}$, and the force in the $z$-direction $F_{z} . F_{x}$ and $F_{z}$ were produced by the trough and other particles and satisfied

$$
\begin{aligned}
& m_{\mathrm{ps}} a_{x}=F_{x}-m_{\mathrm{ps}} g \sin \theta, \\
& m_{\mathrm{ps}} a_{z}=F_{z}-m_{\mathrm{ps}} g \cos \theta,
\end{aligned}
$$

where $m_{\mathrm{ps}}$ is the mass of SP and $a_{x}$ and $a_{z}$ are the acceleration in the $x$-direction and $z$-direction, respectively. Since the directional conveyance occurred in the $x$-direction, we are concerned only with the first expression in (12).

According to the EDEM postprocessing module, $m_{\mathrm{ps}}$ was determined to be $1.91 \times 10^{-5} \mathrm{~kg}$. The relationship between $F_{x}$ and $t$ is shown in Figure 12(a). If the particles were to vibrate together with the trough, $F_{x}$ would be symmetric about the axis where $F_{x}=0$. However, $F_{x}$ was asymmetric, and the positive peak force $\left(F_{x, u}\right)$ was greater than the negative peak force $\left(F_{x, d}\right)$ over each vibration period. An asymmetric force was induced by the finlike asperities on the trough surface.

The force can alter the object kinestate according to Newton's laws of motion. The average velocity component of SP along the $x$-direction $\left(v_{x}\right)$ is shown in Figure 12(b). The effect of the asymmetric force $F_{x}, v_{x}$ was also asymmetric, and its value was generally positive. However, $v_{x}$ of the trough was always symmetric and sinusoidal. 


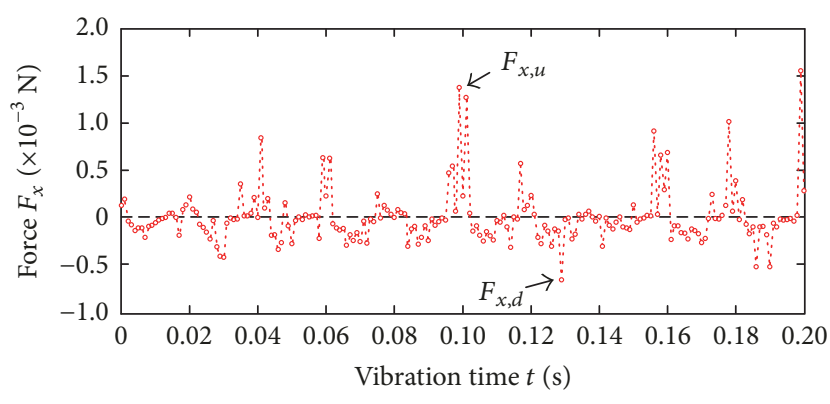

$\ldots \ldots$ SP

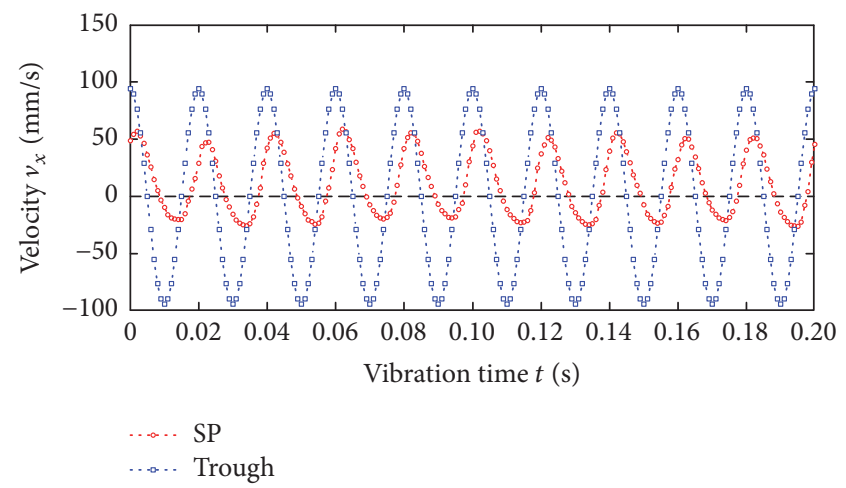

(b)

(a)

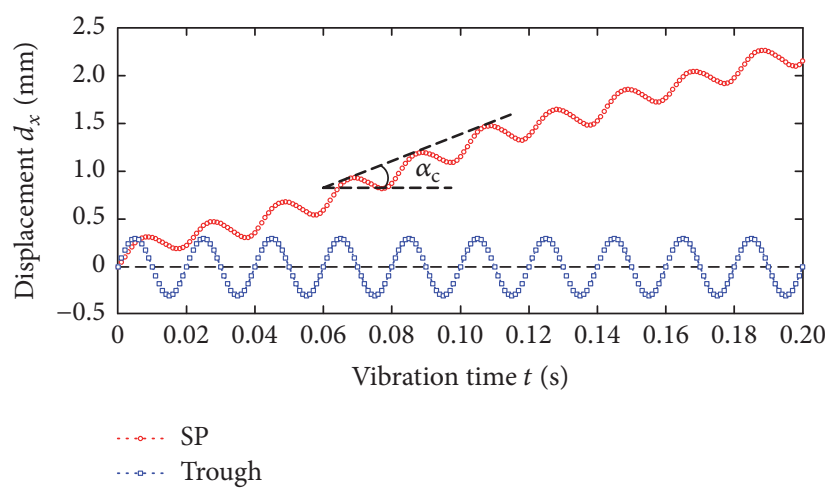

(c)

FIGURE 12: (a) Relationship between the force component of the SP along the $x$-direction and the vibration time. Average velocity components (b) and displacement components (c) of SP and the trough along the $x$-direction.

Furthermore, the average displacement component of the SP along the $x$-direction $\left(d_{x}\right)$ could be obtained based on $v_{x}$ using

$$
d_{x}(t)=\int_{0}^{t} v_{x}(t) \mathrm{d} t
$$

The relationship between $d_{x}$ and $t$ is shown in Figure 12(c). The motion of SP could be described as the combination of two submotions. One of the submotions was the local oscillation, and the other was the directional moving toward the $+x$-direction. The latter submotion was observed to be more effective. The conveyance velocity $\left(v_{\mathrm{c}}\right)$ was equal to the slope of the envelope line $\left(\tan \alpha_{\mathrm{c}}\right)$. In contrast, the trough oscillated around its equilibrium position only.

In fact, $v_{c}$ was not a constant value throughout the conveyance process and was instead related to the packing state of the particles remaining in the trough. This characteristic is generally described by the coordination number $(\mathrm{CN})$, which is defined as the number of particles in contact with a given particle [41]. In other words, if the distance between two particle centers is less than a critical distance, the two particles are considered to be in contact. The critical distance generally ranges from $1.005 d_{\mathrm{p}}$ to $1.05 d_{\mathrm{p}}$. This critical distance is suitable for static and quasi-static granular systems in which each particle's position is nearly unchanged. However, frequent collision occurs among particles in the trough under vibration, implying that particle $i$ has the opportunity to be in contact with particle $j$ at some subsequent time point despite not currently being in contact. Thus, the critical distance can be greater than $1.05 d_{\mathrm{p}}$. In this study, the critical distance is considered as the length of the body diagonal $\left(1.73 d_{\mathrm{p}}\right)$ of a cube whose edge length equals $d_{\mathrm{p}}$, as shown in Figure 13.

At any moment, the $\mathrm{CN}$ was also not a constant value but ranged from 0 to a maximum value $\left(\mathrm{CN}_{\max }\right)$. Based on this concept, a dimensionless parameter $R_{\mathrm{CN}}$ was introduced to evaluate the packing state and was defined as follows:

$$
R_{\mathrm{CN}}=\frac{N_{\mathrm{CN}}}{\left(N_{\mathrm{tot}}-N_{\mathrm{c}}\right)}
$$

where $N_{\mathrm{CN}}$ was the number of the particles whose $\mathrm{CN}$ was greater than $n_{\mathrm{p}}\left(0 \leq n_{\mathrm{p}} \leq \mathrm{CN}_{\max }\right)$. Figure 14 shows the distribution of $R_{\mathrm{CN}}$ at $t=4 \mathrm{~s}$, at which point the $\mathrm{CN}$ ranged from 0 to 10. For a clearer understanding, a median $\mathrm{CN}$ (CN50) was introduced, defined as the $\mathrm{CN}$ at which the corresponding $R_{\mathrm{CN}}$ equals 0.5 in the CN distribution $\left(n_{\mathrm{p}}-R_{\mathrm{CN}}\right)$ curve. A larger CN50 indicates that the particles are packed together more closely.

Throughout the simulation, the relationship between $d_{x}$ and $t$ was tracked and is shown in Figure 15. As the vibration time $t$ increased, the particles were gradually discharged from the trough, and CN50 subsequently declined. In contrast, $v_{c}$ increased until all of the particles were discharged. However, 


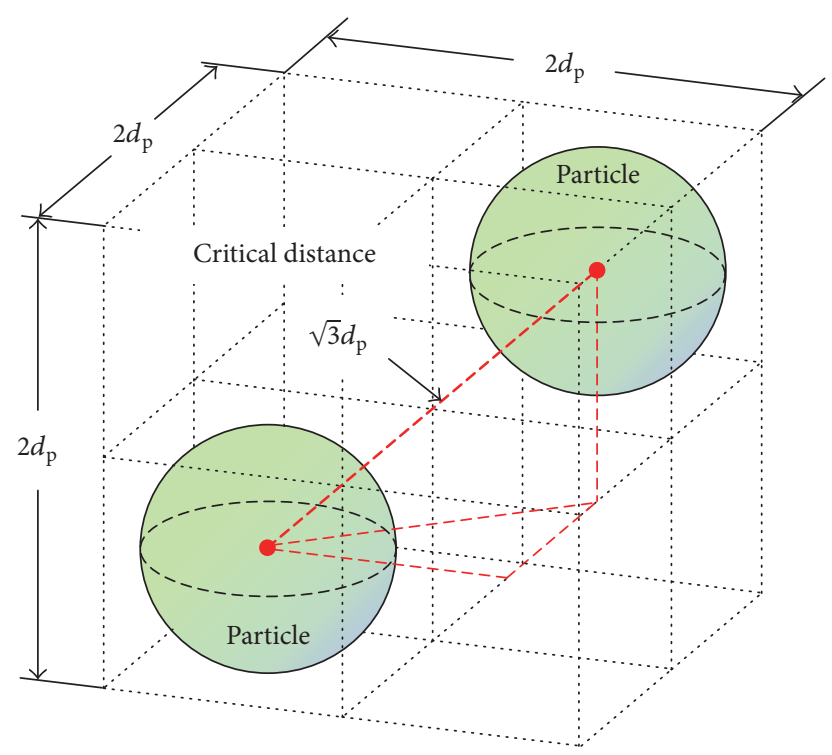

FIgURE 13: Critical distance to determine the CN.

$v_{c}$ did not change sharply with $t$ but rather maintained a steady value over an extended time. For example, $v_{\mathrm{c}}=$ $11.85 \mathrm{~mm} / \mathrm{s}$ from $t=1.5 \mathrm{~s}$ to $6.5 \mathrm{~s}$ under this condition. Therefore, instead of $R_{\mathrm{c}}$, this steady $v_{\mathrm{c}}\left(v_{\mathrm{cs}}\right)$ served as a more intuitive parameter to evaluate the particle directional conveyance performance in DEM simulations.

$v_{\mathrm{c}}$ at time point $t$ was obtained by calculating the slope of the envelope line containing three adjacent vibration periods $(T)$ in the $t-d_{x}$ curve, as shown in Figure 12(c).

4.2. Influence of the Asperity Height on the Conveyance Process. With $Y_{\mathrm{a}}=0.2$ and $Y_{\mathrm{b}}=4$, the resulting relationship between $v_{\mathrm{cs}}$ and $Y_{\mathrm{h}}$ is shown in Figure 16. When $Y_{\mathrm{h}}=0.2$ and $0.4, v_{\mathrm{cs}}$ was nearly the same. When $Y_{\mathrm{h}}$ was greater than $0.4, v_{\mathrm{cs}}$ declined as $Y_{\mathrm{h}}$ increased. Under this condition, the finlike asperity shape was the same but with proportional size, implying that a greater $Y_{\mathrm{h}}$ results in a larger asperity and that the distance between two asperities $\left(d_{\mathrm{a}}\right)$ also increases. In this work, we introduce the parameter $\varphi_{\mathrm{a}}$ to quantitatively describe the relationship between $d_{\mathrm{a}}$ and $d_{\mathrm{p}}$, as the ratio of $d_{\mathrm{a}}$ to $d_{\mathrm{p}}$ :

$$
\varphi_{\mathrm{a}}=\frac{d_{\mathrm{a}}}{d_{\mathrm{p}}}=Y_{\mathrm{h}}\left(\frac{1}{Y_{\mathrm{a}}}+\frac{1}{Y_{\mathrm{b}}}\right) .
$$

Since the vibration parameters were invariable, the energy provided for the particles was constant and finite. Thus, it was less likely for the particles to leap over the asperities with larger $d_{\mathrm{a}}$. According to the results in Figure 16, the directional conveyance was weakened when $\varphi_{\mathrm{a}}$ was greater than approximately 2 .

4.3. Influence of the Asperity Slope Inclination Angles on the Conveyance Process. Keeping $Y_{\mathrm{h}}=0.4$ and $Y_{\mathrm{b}}=4$, the resulting relationships between $Y_{\mathrm{a}}$ and $\nu_{\mathrm{cs}}$ and $Y_{\mathrm{a}}$ and $\varphi_{\mathrm{a}}$ are shown in Figure 17(a). The figure indicates that as the asperity slope inclination angle $\alpha$ increased, the distance between two asperities $d_{\mathrm{a}}$ decreased monotonously. However, the conveyance velocity $v_{\mathrm{cs}}$ varied circuitously. When the coefficient $Y_{\mathrm{a}}$ was less than 0.3 , that is, when $\varphi_{\mathrm{a}}$ was greater than $1.43, v_{\mathrm{cs}}$ increased with increasing $Y_{\mathrm{a}}$. When $Y_{\mathrm{a}}$ was greater than 0.3 , $v_{\mathrm{cs}}$ instead was reduced, and the particles even flowed toward the opposite direction when $Y_{\mathrm{a}}=0.5$. This result also shows that a much smaller $d_{\mathrm{a}}$ does not contribute to the particle directional conveyance. A favorable range of $\varphi_{\mathrm{a}}$ under this condition was from 1.1 to 2.1 .

Keeping $Y_{\mathrm{h}}=0.4$ and $Y_{\mathrm{a}}=0.2$, the resulting relationships between $Y_{\mathrm{b}}$ and $\nu_{\mathrm{cs}}$ and $Y_{\mathrm{b}}$ and $\varphi_{\mathrm{a}}$ are shown in Figure 17(b). The figure indicates that $d_{\mathrm{a}}$ declined with increasing $\beta$. However, since $\beta>45^{\circ}, Y_{\mathrm{b}}>1$, and the effect on $d_{\mathrm{a}}$ was small relative to the effect on $\alpha$. Therefore, $v_{\mathrm{cs}}$ did not change substantially either, particularly when $Y_{\mathrm{b}} \geq 2$.

A familiar configuration of the finlike asperity is when $\alpha+\beta=90^{\circ}$, that is, when the finlike asperity shape is a right triangle. By defining $Y_{\mathrm{b}}=1 / Y_{\mathrm{a}}$ and $Y_{\mathrm{a}}=[0.2,0.25,0.3,0.35$, 0.4 ], we ensure that $Y_{\mathrm{b}}>2$. As $\beta$ was not a sensitive parameter to $v_{\mathrm{cs}}$ when $Y_{\mathrm{b}} \geq 2$, the focus of this work was the effects of $h$ and $\alpha$. In addition, $Y_{\mathrm{h}}$ was set as $0.4,0.5,0.6,0.7$, and 0.8 for a denser micromesh analysis. The relationships between $Y_{\mathrm{a}}$ and $v_{\mathrm{cs}}$ and $Y_{\mathrm{a}}$ and $\varphi_{\mathrm{a}}$ under various $Y_{\mathrm{h}}$ are shown in Figure 18. The curves in Figure 18(a) indicate that with increasing $h$, the influence of $\alpha$ on $v_{\mathrm{cs}}$ weakened gradually, and $h$ had more of a significant influence than $\alpha$ within this scope.

Figure 18(b) reconfirms that $d_{\mathrm{a}}$ declined with increasing $\alpha$ and increased as $h$ rose. Correspondingly, when $\varphi_{\mathrm{a}}$ ranged from 1 to $2, v_{\text {cs }}$ initially increased and then decreased. When $\varphi_{\mathrm{a}}$ decreased to $2, v_{\mathrm{cs}}$ increased monotonously, indicating that the particle conveyance performance was improved within $1<\varphi_{\mathrm{a}}<2$. However, $d_{\mathrm{a}}$ could not be used to accurately evaluate $v_{\mathrm{cs}}$. For example, when $Y_{\mathrm{h}}=0.4$ and $Y_{\mathrm{a}}=0.25$ and when $Y_{\mathrm{h}}=0.6$ and $Y_{\mathrm{a}}=0.4, \varphi_{\mathrm{a}}$ was almost 1.7 , but $v_{\mathrm{cs}}$ was $14.75 \mathrm{~mm} / \mathrm{s}$ and $7.15 \mathrm{~mm} / \mathrm{s}$, respectively. Despite the fact that $d_{\mathrm{a}}$ is not suitable to quantitatively evaluate $v_{\mathrm{cs}}$, this parameter can provide guidance to roughly optimize $h$ and $\alpha$ to improve the particle conveyance performance.

4.4. Discussion. According to the DEM simulation, the particle directional conveyance under vibration is due to the asymmetric forces in the longitudinal direction. This mechanism is similar to material conveyance in a nonharmonic vibratory conveyor [10]. However, the asymmetric force is caused by the finlike asperities in our study rather than the trough's nonsinusoidal vibration in the traditional vibratory conveyance. Using the trough with finlike asperities, the vibration form can be sinusoidal, which benefits the simplification of the driving mechanism. This simplification shows great significance for nonterrestrial tasks.

$\mathrm{CN}$ is an appropriate parameter to evaluate the influence of the particle packing state on the conveyance capacity. In particular, the $\mathrm{CN}$ characterizes the advantage over the particle layer thickness [42] when there is only one layer. Of course, the use of $\mathrm{CN}$ is feasible only in simulation studies and not experimental studies. The distribution of $\mathrm{CN}$ at a given time point is described by the median $\mathrm{CN}, \mathrm{CN} 50$. A large CN50 indicates that more particles are or will be in contact, which can reduce directional conveyance. 


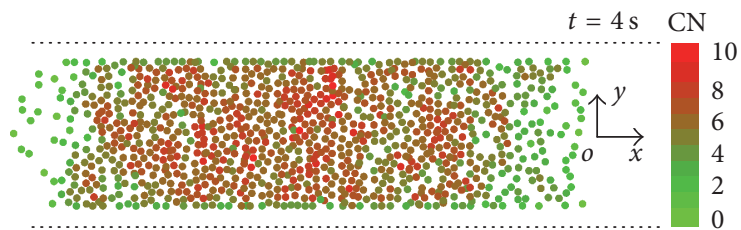

(a)

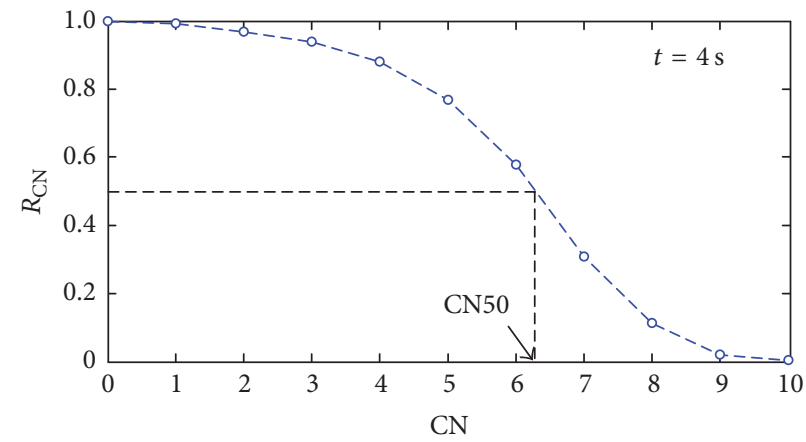

(b)

FIgURE 14: (a) The CN distribution of particles in the trough and (b) the CN distribution curve and the median CN (CN50).

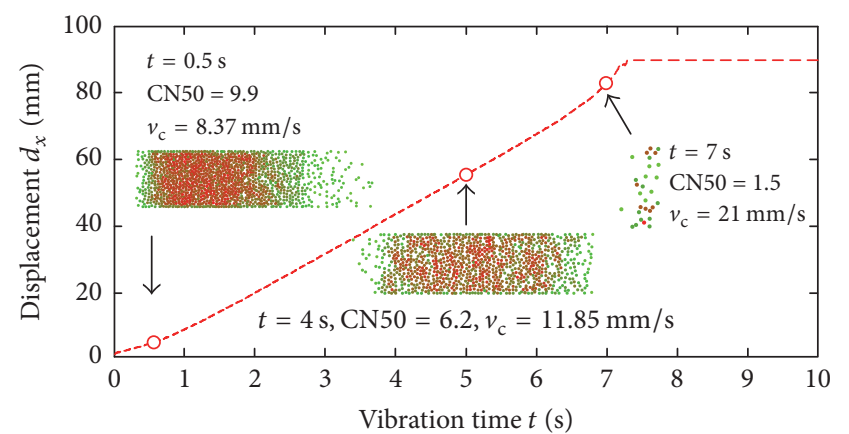

FIGURE 15: Particles average displacement in the $x$-direction throughout the simulation and the variation of the $\mathrm{CN}$ distribution and $v_{\mathrm{c}}$ at various time points $(t=0.5 \mathrm{~s}, t=4 \mathrm{~s}$, and $t=7 \mathrm{~s})$.

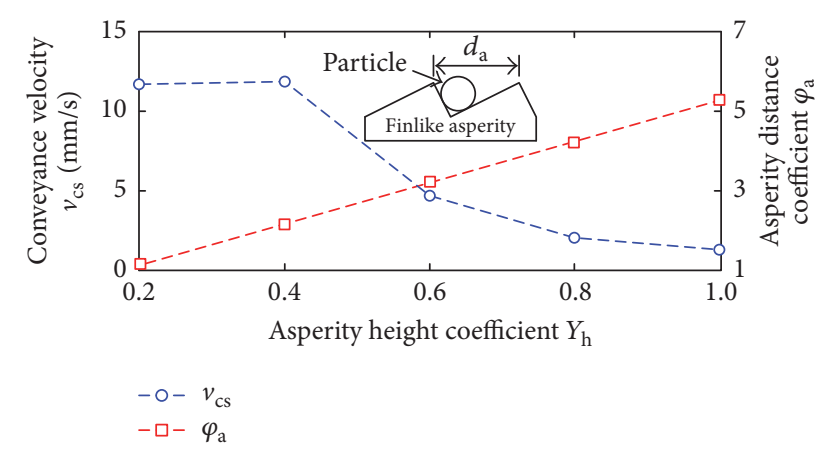

FIGURE 16: The influence of the finlike asperity height on the particle conveyance velocity and the distance between two asperities $\left(Y_{\mathrm{a}}=\right.$ 0.2 and $\left.Y_{\mathrm{b}}=4\right)$.

The simulation results also show the influence of the finlike asperity height $h$ and slope inclination angles $\alpha$ and $\beta$ on the particle directional conveyance capacity. The values of $h, \alpha$, and $\beta$ determine the asperity interval $d_{\mathrm{a}}$. An excessively small or large $d_{\mathrm{a}}$ does not benefit particle directional conveyance, and an intermediately sized $d_{\mathrm{a}}\left(1 d_{\mathrm{p}} \sim 2 d_{\mathrm{p}}\right)$ is more appropriate. The importance of the right asperity size is also validated in Farkas et al.' study despite the vibration direction being vertical [25], which indicates that the finlike asperity size should match the particle diameter $d_{\mathrm{p}}$ to improve the conveyance capacity.

\section{Conclusions}

For the purpose of granular material transport on future lunar base construction, a type of vibratory conveyance method that considers finlike asperities on a trough surface was introduced. In this study, we employed the DEM to investigate the particle directional conveyance characteristics in the trough. The following conclusions were drawn.

(a) The restitution coefficient between the trough and the particle $e_{\mathrm{p}-\mathrm{t}}$ is the factor that most strongly influences the particle directional conveyance capacity. The two most important factors are the static friction coefficient $\mu_{\mathrm{s}}$ and the rolling friction coefficient $\mu_{\mathrm{r}}$.

(b) Due to the finlike asperities, particles are exposed to an asymmetric force $F_{x}$ under longitudinal and sinusoidal vibrations. The cumulative effect of $F_{x}$ over time governs the particle directional conveyance. During the conveyance process, the median $\mathrm{CN}$, CN50, affects the conveyance velocity $v_{c}$; a greater CN50 induces a lower $v_{c}$ because the multitude of contacting particle collisions weakens the effects of conveyance.

(c) The particle steady conveyance velocity $v_{\mathrm{cs}}$ is affected by the asperity height $h$ and the slope inclination angles $\alpha$ and $\beta$. In fact, these parameters directly 


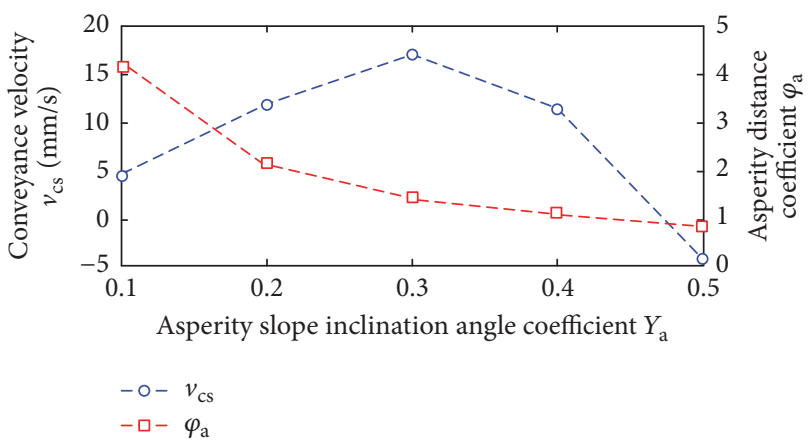

(a)

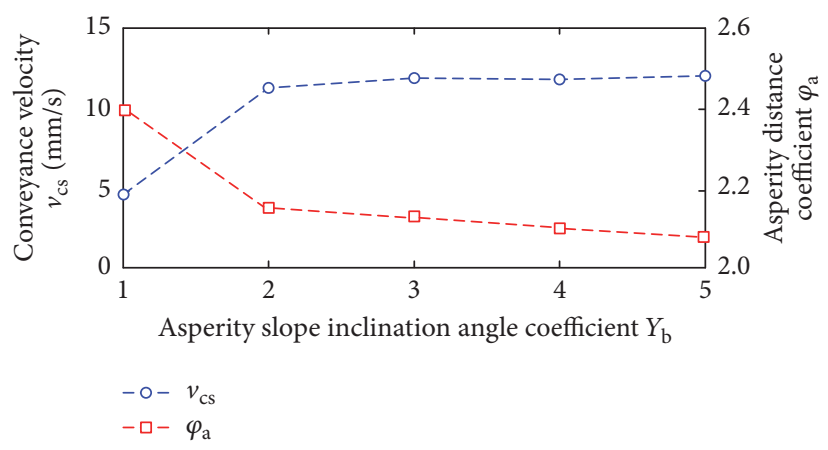

(b)

FIGURE 17: Influence of the asperity slope inclination angle on the conveyance velocity and the distance between two asperities. (a) Influence of $\alpha$ when $Y_{\mathrm{h}}=0.4$ and $Y_{\mathrm{b}}=4$ and (b) influence of $\beta$ when $Y_{\mathrm{h}}=0.4$ and $Y_{\mathrm{a}}=0.2$.

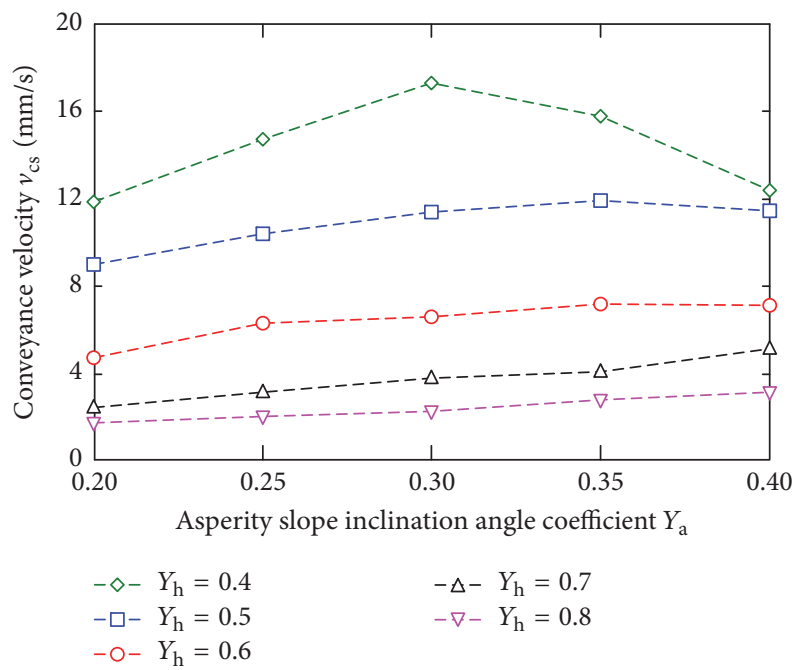

(a)

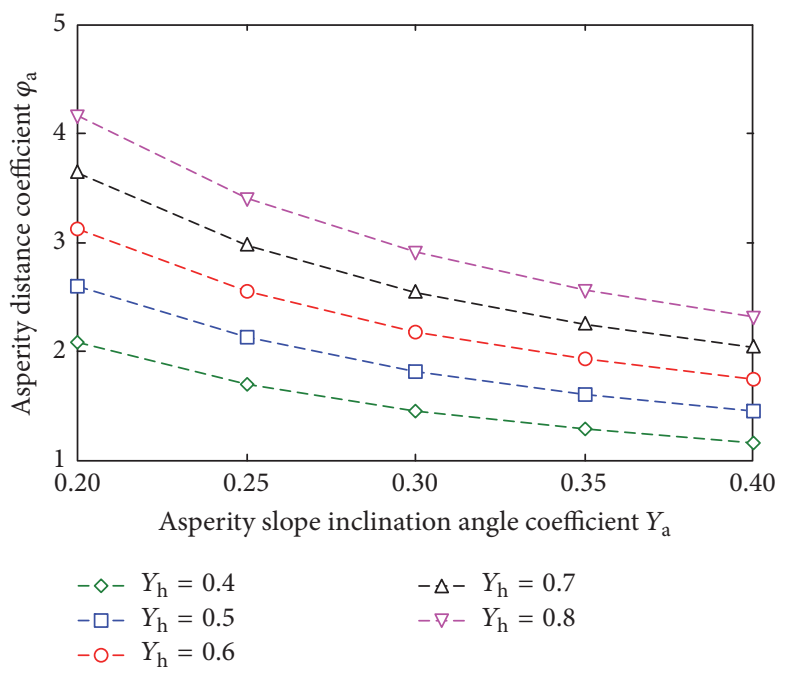

(b)

FIgURE 18: (a) The influence of $Y_{\mathrm{h}}$ and $Y_{\mathrm{a}}$ on $v_{\mathrm{cs}}$ and (b) the effects of $Y_{\mathrm{h}}$ and $Y_{\mathrm{a}}$ on $\varphi_{\mathrm{a}}$.

determine the distance between the two finlike asperities $d_{\mathrm{a}}$, and an undersized or oversized $d_{\mathrm{a}}$ tends to reduce $v_{\mathrm{cs}}$. In this study, $v_{\mathrm{cs}}$ increased when $d_{\mathrm{a}}$ was between one and two times the particle diameter $d_{\mathrm{p}}$.

\section{Conflicts of Interest}

The authors declare no conflicts of interest.

\section{Acknowledgments}

The authors are grateful for the support of the National Natural Science Foundation of China (Grant no. 51575122) and the Self-Planned Task of State Key Laboratory of Robotics and System (HIT) (Grant no. SKLRS201616B).

\section{References}

[1] R. P. Mueller and I. Townsend, "Lunar regolith simulant feed system for a hydrogen reduction reactor system," in Proceedings of the 47th AIAA Aerospace Sciences Meeting, Orlando, FL, USA, January 2009.

[2] G. Sanders, W. Larson, and K. Sacksteder, NASA Lunar Mining and Construction Activities and Plans, 2009.

[3] S. Jiang, Y. Shen, X. Wu et al., "Technical schemes of investigation and in-situ utilization for lunar surface generalized resource," Journal of Deep Space Exploration, vol. 2, no. 4, pp. 291-301, 2015.

[4] Y. Zhao, F. Huang, and Z. Zhao, "Dynamic analysis on vertical vibratory conveyor," Advanced Materials Research, vol. 694, pp. 3-6, 2013.

[5] E. M. Sloot and N. P. Kruyt, "Theoretical and experimental study of the transport of granular materials by inclined vibratory conveyors," Powder Technology, vol. 87, no. 3, pp. 203-210, 1996.

[6] G. H. Lim, "On the conveying velocity of a vibratory feeder," Computers \& Structures, vol. 62, no. 1, pp. 197-203, 1997.

[7] J. A. Vilán Vilán, A. Segade Robleda, P. J. García Nieto, and C. Casqueiro Placer, "Approximation to the dynamics of transported parts in a vibratory bowl feeder," Mechanism and Machine Theory, vol. 44, no. 12, pp. 2217-2235, 2009. 
[8] X. Kong, X. Zhang, Q. Li, and B. Wen, "Dynamical analysis of vibratory feeder and feeding parts considering interactions by an improved increment harmonic balance method," Proceedings of the Institution of Mechanical Engineers, Part C: Journal of Mechanical Engineering Science, vol. 229, no. 6, pp. 1029-1040, 2015.

[9] D. Reznik and J. Canny, "Coulomb pump: A novel parts feeding method using a horizontally-vibrating surface," in Proceedings of the 1998 IEEE International Conference on Robotics and Automation. Part 1 (of 4), vol. 1, pp. 869-874, May 1998.

[10] B. Guo, Z. Duan, J. Zheng, and Y. He, "Analysis of material movement of non-harmonic horizontally vibrated conveyer," Jixie Gongcheng Xuebao/Journal of Mechanical Engineering, vol. 48, no. 1, pp. 104-110, 2012.

[11] A. Mitani, T. Yoshimura, and S. Hirai, "Feeding of submillimeter-sized microparts along a saw-tooth surface using only horizontal vibration: Analysis of convexities on the surface of microparts," in Proceedings of the 3rd IEEE International Conference on Automation Science and Engineering (IEEE CASE '07), pp. 69-76, IEEE, USA, September 2007.

[12] H. Chen, S. Jiang, Y. Shen, W. Zhang, and P. Li, "A simulation study on conveying characteristics of particles on a vibrating plate with zigzag morphology," in Proceedings of the 2016 IEEE International Conference on Information and Automation (IEEE ICIA '16), pp. 468-473, IEEE, China, August 2016.

[13] E. Clément, J. Duran, and J. Rajchenbach, "Experimental study of heaping in a two-dimensional sand pile," Physical Review Letters, vol. 69, no. 8, pp. 1189-1192, 1992.

[14] K. Liffman, G. Metcalfe, and P. Cleary, "Granular convection and transport due to horizontal shaking," Physical Review Letters, vol. 79, no. 23, pp. 4574-4576, 1997.

[15] M. E. Möbius, X. Cheng, P. Eshuis, G. S. Karczmar, S. R. Nagel, and H. M. Jaeger, "Effect of air on granular size separation in a vibrated granular bed," Physical Review E: Statistical, Nonlinear, and Soft Matter Physics, vol. 72, no. 1, Article ID 011304, 2005.

[16] C. Liu, F. Zhang, P. Wu, and L. Wang, "Effect of hoisting tube shape on particle climbing," Powder Technology, vol. 259, pp. 137-143, 2014.

[17] P. A. Cundall and O. D. L. Strack, "The distinct numerical model for granular assemblies," Géotechnique, vol. 79, no. 1, pp. 47-65, 1979.

[18] E. Simsek, S. Wirtz, V. Scherer, H. Kruggel-Emden, R. Grochowski, and P. Walzel, "An experimental and numerical study of transversal dispersion of granular material on a vibrating conveyor," Particulate Science and Technology, vol. 26, no. 2, pp. 177-196, 2008.

[19] Y. Shimizu, “Three-Dimensional DEM Simulation of Conveying Granular Materials by Horizontal Screw," in Proceedings of the Third International Conference on Discrete Element Methods, pp. 415-422, Santa Fe, New Mexico, USA, 2002.

[20] Y. Han, F. Jia, Y. Zeng, L. Jiang, Y. Zhang, and B. Cao, “DEM study of particle conveying in a feed screw section of vertical rice mill," Powder Technology, vol. 311, pp. 213-225, 2017.

[21] Y. Xu, J. Musser, T. Li, J. T. Padding, and W. A. Rogers, "Particles climbing along a vertically vibrating tube: numerical simulation using the Discrete Element Method (DEM)," Powder Technology, vol. 320, pp. 304-312, 2017.

[22] F. Zhou, S. Hu, Y. Liu, C. Liu, and T. Xia, "CFD-DEM simulation of the pneumatic conveying of fine particles through a horizontal slit," Particuology, vol. 16, pp. 196-205, 2014.
[23] Y. C. Zhou, B. H. Xu, A. B. Yu, and P. Zulli, "An experimental and numerical study of the angle of repose of coarse spheres," Powder Technology, vol. 125, no. 1, pp. 45-54, 2002.

[24] S. M. Derakhshani, D. L. Schott, and G. Lodewijks, "Micromacro properties of quartz sand: Experimental investigation and DEM simulation," Powder Technology, vol. 269, pp. 127-138, 2015.

[25] Z. Farkas, P. Tegzes, A. Vukics, and T. Vicsek, "Transitions in the horizontal transport of vertically vibrated granular layers," Physical Review E: Statistical Physics, Plasmas, Fluids, and Related Interdisciplinary Topics, vol. 60, no. 6 B, pp. 7022-7031, 1999.

[26] N. Mitarai and H. Nakanishi, "Hard-sphere limit of soft-sphere model for granular materials: Stiffness dependence of steady granular flow," Physical Review E: Statistical, Nonlinear, and Soft Matter Physics, vol. 67, no. 2, Article ID 021301, pp. 213011213018, 2003.

[27] A. B. Stevens and C. M. Hrenya, "Comparison of soft-sphere models to measurements of collision properties during normal impacts," Powder Technology, vol. 154, no. 2-3, pp. 99-109, 2005.

[28] S. R. Schwartz, D. C. Richardson, and P. Michel, "An implementation of the soft-sphere discrete element method in a highperformance parallel gravity tree-code," Granular Matter, vol. 14, no. 3, pp. 363-380, 2012.

[29] Y. Zeng, F. Jia, Y. Zhang, X. Meng, Y. Han, and H. Wang, "DEM study to determine the relationship between particle velocity fluctuations and contact force disappearance," Powder Technology, vol. 313, pp. 112-121, 2017.

[30] K. L. Johnson, K. Kendall, and A. D. Roberts, "Surface energy and the contact of elastic solids," Proceedings of the Royal Society A Mathematical, Physical and Engineering Sciences, vol. 324, no. 1558, pp. 301-313, 1971.

[31] R. D. Mindlin, "Elastic spheres in contact under varying oblique forces," Journal of Applied Mechanics, vol. 20, pp. 327-344, 1953.

[32] H. Kruggel-Emden, E. Simsek, S. Rickelt, S. Wirtz, and V. Scherer, "Review and extension of normal force models for the Discrete Element Method," Powder Technology, vol. 171, no. 3, pp. 157-173, 2007.

[33] C. Thornton, S. J. Cummins, and P. W. Cleary, "An investigation of the comparative behaviour of alternative contact force models during inelastic collisions," Powder Technology, vol. 233, pp. 30-46, 2013.

[34] J. Horabik, P. Parafiniuk, and M. Molenda, "Discrete element modelling study of force distribution in a 3D pile of spherical particles," Powder Technology, vol. 312, pp. 194-203, 2017.

[35] C. J. Coetzee and D. N. J. Els, "Calibration of discrete element parameters and the modelling of silo discharge and bucket filling," Computers and Electronics in Agriculture, vol. 65, no. 2, pp. 198-212, 2009.

[36] M. Ucgul, J. M. Fielke, and C. Saunders, “Three-dimensional discrete element modelling of tillage: Determination of a suitable contact model and parameters for a cohesionless soil," Biosystems Engineering, vol. 121, pp. 105-117, 2014.

[37] D. Zhao, X. Hou, D. Tang, J. Yuan, S. Jiang, and Z. Deng, "DEM parameter matching of high-dense lunar soil simulant," in Proceedings of the 2015 IEEE International Conference on Information and Automation, ICIA 2015 - In conjunction with 2015 IEEE International Conference on Automation and Logistics, pp. 1920-1925, China, August 2015.

[38] Y. Tatemoto, Y. Niwa, and T. Takeshita, "Circulation of particles in a vibrated bed with an inner tube," Powder Technology, vol. 192, no. 3, pp. 279-286, 2009. 
[39] C. O'Sullivan and J. D. Bray, "Selecting a suitable time step for discrete element simulations that use the central difference time integration scheme," Engineering Computations (Swansea, Wales), vol. 21, no. 2-4, pp. 278-303, 2004.

[40] X. Z. Wang and J. H. Yang, "Hydraulic cylinder boring quality range analysis based on orthogonal test," Advanced Materials Research, vol. 945-949, pp. 1289-1292, 2014.

[41] R. Y. Yang, R. P. Zou, and A. B. Yu, "Computer simulation of the packing of fine particles," Physical Review E: Statistical Physics, Plasmas, Fluids, and Related Interdisciplinary Topics, vol. 62, no. 3 B, pp. 3900-3908, 2000.

[42] D. Liao, X. Qi, and Z. Qin, "Comparative analysis of singleparticle and multi-particle model of vibrating delivery," Mining \& Processing Equipment, vol. 43, no. 4, pp. 56-60, 2015. 


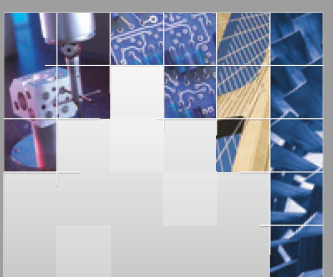

\section{Enfincering}
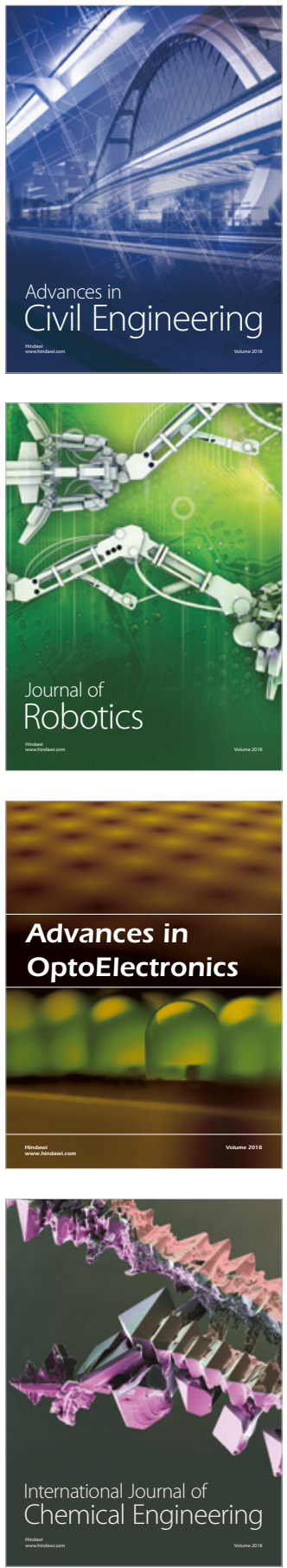

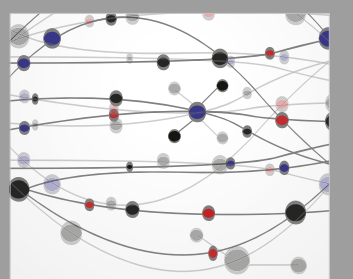

\section{Rotating \\ Machinery}

The Scientific World Journal

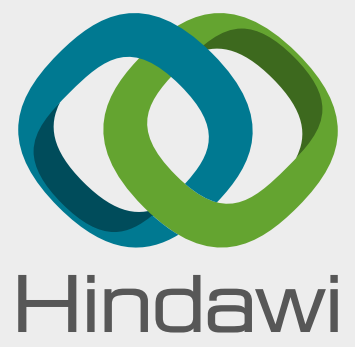

Submit your manuscripts at

www.hindawi.com
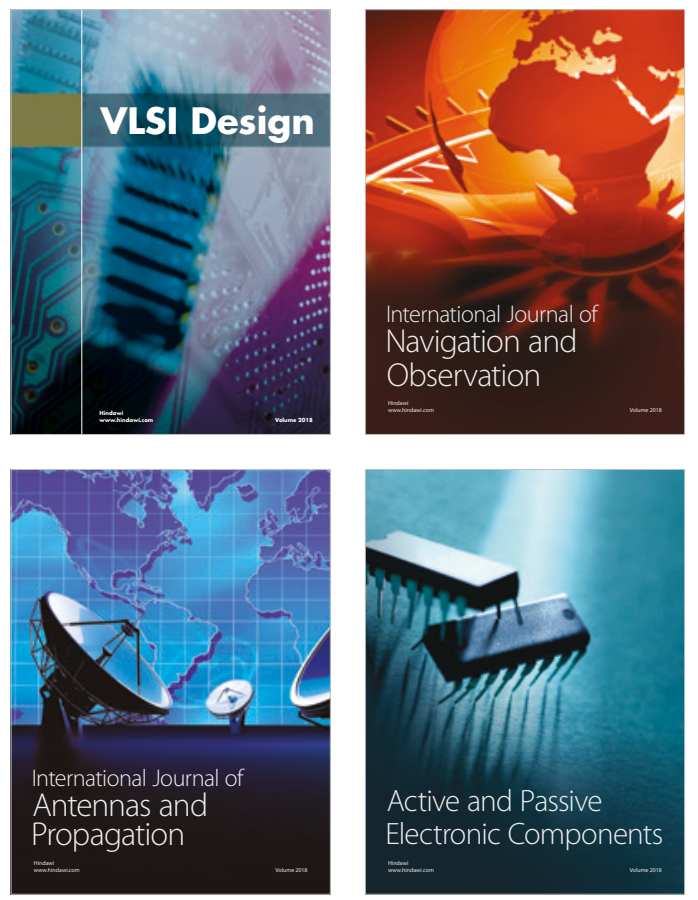
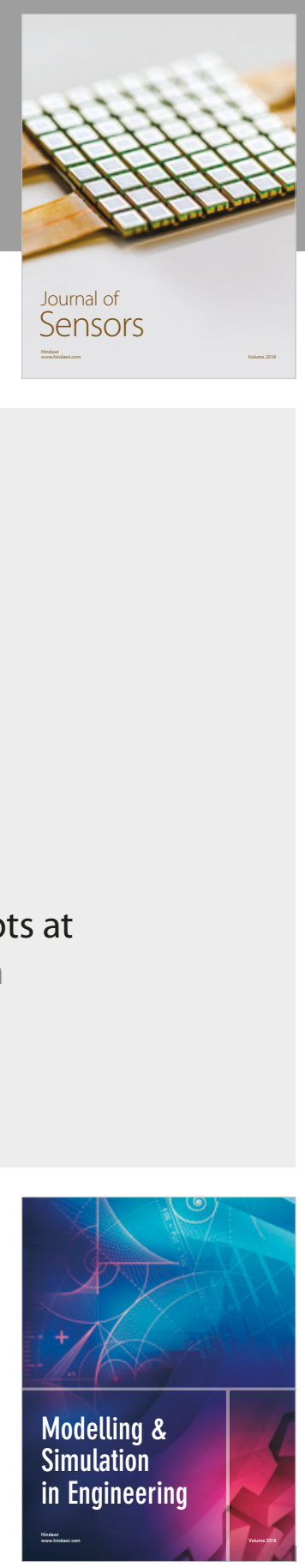

\section{Advances \\ Multimedia}
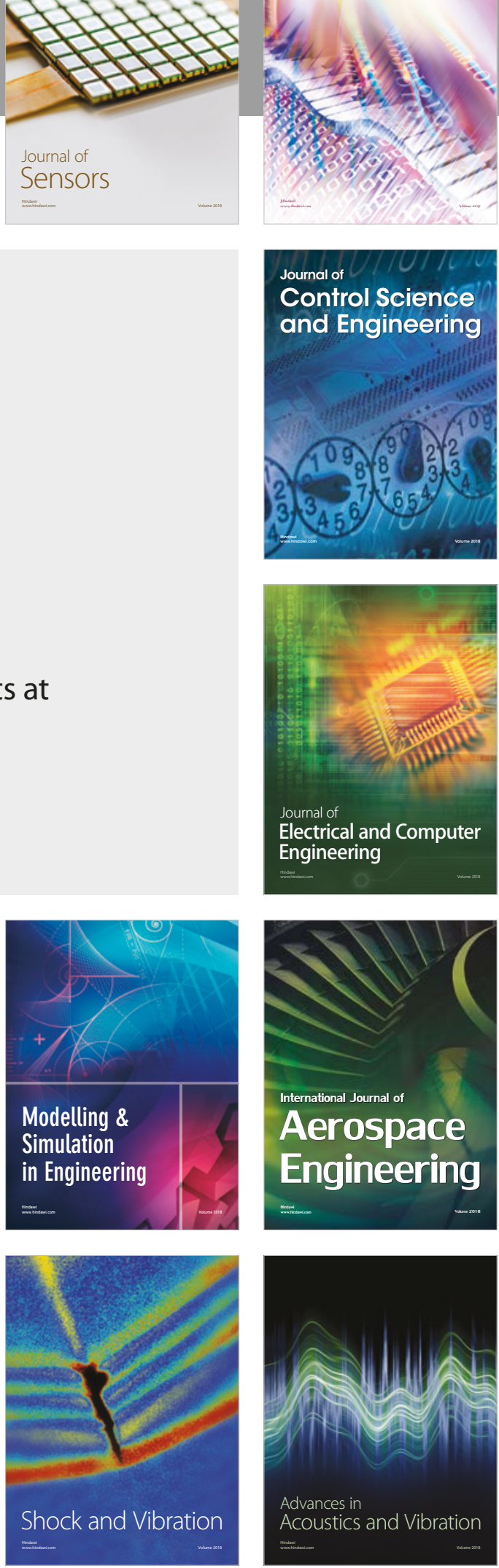